\title{
Álvaro Mutis, poeta insular: su poesía en la tradición colombiana
}

\author{
Álvaro Mutis, Insular Poet: His Poetry in the Colombian Tradition \\ Álvaro Mutis, poeta insular: sua poesia na tradição colombiana
}

\section{Juan Felipe Robledo Cadavid}

PONTIFICIA UNIVERSIDAD JAVERIANA, BOGOTÁ

Profesor de poesía española, latinoamericana y colombiana en el

Departamento de Literatura de la Facultad de Ciencias Sociales de

la Pontificia Universidad Javeriana, Bogotá, Colombia; doctorando en el programa de Doctorado en Literatura y Teatros Españoles e

Hispanoamericanos en el Contexto Europeo de la UNED, Madrid,

España. Correo electrónico: robledo.j@javeriana.edu.co

Documento accesible en línea desde la siguiente dirección: http://revistas.javeriana.edu.co 


\section{Resumen}

Este artículo busca ubicar la poesía de Álvaro Mutis dentro de los movimientos poéticos colombianos. Partiendo de un recorrido por las diferentes generaciones poéticas durante la primera mitad del siglo $\mathrm{XX}$, se trata de identificar los legados que han dejado la mayor impronta en su poesía. De especial importancia es la discusión sobre su lenguaje poético innovador en contraste con las posturas políticas conservadoras que recorren su obra y pensamiento, lo que lo convierte en un autor insular en el panorama de la historia de la literatura en Colombia.

Palabras clave: Álvaro Mutis; poesía colombiana; generaciones poéticas del siglo XX

\section{Abstract}

The purpose of this paper is to determine the place of Alvaro Mutis's poetry in the general landscape of Colombian poetic movements. I begin with an overview of the poetic generation in the first half of the 20th century in order to identify the legacies that have had the most significant impact on his poetry. Special emphasis is made on the contrast between Mutis's innovative poetic language and his conservative political views as the main characteristic of his insularity in Colombian literary history.

Keywords: Álvaro Mutis; Colombian Poetry; Colombian Poetic Movements of the 20th

Century

\section{Resumo}

Este artigo visa colocar a poesia de Álvaro Mutis dentro dos movimentos poéticos colombianos. Partindo de um percurso pelas diferentes gerações poéticas durante a primeira metade do século XX, objetiva-se identificar os legados que deixaram o maior chancela na sua poesia. De particular importância é a discussão sobre a sua linguagem poética inovadora em contraste com as posturas políticas conservadoras que atravessam a sua obra $\mathrm{e}$ pensamento, o que torna-o um ator insular no panorama da historia da literatura na Colômbia.

Palavras-chave: Álvaro Mutis; poesia colombiana; gerações poéticas do século XX

\section{Cómo citar este artículo:}

Robledo, Juan Felipe. "Álvaro Mutis, poeta insular: su poesía en la tradición colombiana”. Cuadernos de Literatura 21.41 (2017): 288-301. https://doi.org/10.11144/Javeriana.cl21-41.ampi 
L A C R Í T I A EX I T E N T E sobre la poesía de Álvaro Mutis ha señalado en numerosas ocasiones el desafío que representa ubicar esta producción dentro de las generaciones y tendencias que se han identificado para la poesía colombiana del siglo XX (véanse Romero; Castillo Mier; Sarmiento Sandoval; Jiménez, "Sobre la presente"; Jurado Valencia). Ya en sus primeros poemas publicados en libro, aparecidos en 1948 en un volumen con el título de La balanza, escrito a cuatro manos con Carlos Patiño, se advierten destellos de una voz poética singular. ${ }^{1}$ Los seis poemas de Mutis en este volumen ("Una palabra", "Tres imágenes", "204", "Nocturno", "Oración de Maqroll" y "El miedo") no parecen tener una relación rastreable con la tradición poética colombiana más inmediata, la de los poetas de la Generación de Piedra y Cielo, la misma de su profesor de colegio Eduardo Carranza (1913-1985), y de Jorge Rojas (1911-1995), Arturo Camacho Ramírez (1910-1982), Carlos Martín (1914-2008). En estos poemas se puede advertir, más bien, una cercanía espiritual, aun cuando no estilística, con la de los poetas de la generación anterior, sus "abuelos" literarios, representada por la generación de Los Nuevos, a la que pertenecieron León de Greiff(1895-1976), Luis Vidales (1904-1990), Jorge Zalamea (1905-1969) y Luis Tejada (1898-1924).

La singularidad que se manifestó en estos primeros poemas se mantuvo a lo largo de toda la obra de Mutis, tanto poética como narrativa, y vista en conjunto, esta pareciera no encajar en ninguna de las vertientes o líneas de la literatura colombiana del siglo XX. Por ello se le ha catalogado como uno de los "poetas insulares", en el mismo sentido que a Luis Carlos López (1879-1950), Porfirio Barba Jacob (1883-1942) y Aurelio Arturo (1906-1974).

El propósito de este artículo es indagar por la naturaleza de esa insularidad. El punto de partida no es cuestionarla, sino señalar que lo que la distinga es la forma poco ortodoxa, entreverada, que adopta la poesía de Mutis frente a la de sus antecesores y contemporáneos. Es decir, lejos de asumir que la singularidad e insularidad de la poesía de Mutis están definidas por una ausencia de correlatos y referentes con respecto a la poesía colombiana, propongo aquí examinar cómo se separa de cierto curso ortodoxo de relacionarse con ella.

Para realizar esta tarea, considero que es necesario hacer un recorrido por la historia de la poesía en Colombia en el siglo XX en aras de entender cómo se ha establecido el cambio de tendencias y estilos y cómo se han definido los distintos grupos o movimientos.

1 El poemario se imprimió en los Talleres Prag de Bogotá y la edición fue destruida casi íntegramente el 9 de abril de ese mismo año durante "El Bogotazo". 


\section{Las generaciones en la poesía colombiana}

La historiografía de la poesía colombiana de la primera mitad del siglo XX ha seguido el sistema de generaciones para darles forma y nombrar a los diversos grupos de poetas, reunidos con una lógica de corte cronológico, no siempre estricta, que hace convivir en ocasiones a algunos autores como miembros de alguna generación y, de manera simultánea, de un movimiento o agrupación literaria nucleada alrededor de una publicación o tertulia. Sin embargo, el criterio de establecimiento de las generaciones poéticas en el siglo XX ha prevalecido de manera notoria. Patricia Trujillo sostiene a este respecto:

[L]a tendencia más constante ha sido la de mantener la división tradicional por generaciones: la del Centenario, la de Los Nuevos, la de Piedra y Cielo, la de Mito, la de los Nadaístas y la Generación desencantada, Generación Postnadaísta o Generación sin nombre. Esta es, a grandes rasgos, la división que adoptó Jaime Mejía Duque en su breve pero interesante libro Momentos y opciones de la poesía en Colombia, de 1979. Esta es, también, la división que adoptan, en líneas generales, las tres historias conjuntas sobre la poesía y la literatura colombianas de fin de siglo: el segundo tomo del Manual de literatura colombiana de 1988, la Historia de la poesía colombiana, editada por la Casa Silva en 1991 y el tomo IV de la Gran enciclopedia de Colombia, correspondiente a la literatura colombiana, coordinado por María Teresa Cristina y publicado en 1992. Cada uno de estos libros dedica algunos capítulos aparte a la obra de poetas que considera, o bien por fuera de los grupos generacionales gracias a la originalidad de su obra, o demasiado importantes para incluirlos en una época determinada. Es el caso de Aurelio Arturo y Mario Rivero en la Historia de la poesía colombiana y el de José Eustasio Rivera y Luis Carlos López en el tomo IV de la Gran enciclopedia de Colombia. (Trujillo 136)

Esta categorización por generaciones indica, a primera vista, que lo que agrupa a los poetas así clasificados no es necesariamente una tendencia estética o una propuesta de corte definido. Como se verá en el recuento que hacemos a continuación, los miembros de las generaciones pertenecían a los mismos círculos sociales e intelectuales, compartían gustos literarios y publicaban en las mismas revistas y periódicos. Lo que los diferenciaría serían sus posiciones políticas.

El siglo XIX había cerrado con dos figuras sobresalientes: José Asunción Silva (1865-1896), modernista de la primera generación (aunque algunos lo consideran de la segunda, posterior a Martí y a Casal), y Guillermo Valencia (1873-1943), modernista tardío, erigido como la principal figura faro de la poesía de fin de siglo tras el suicidio de Silva. Aun cuando ambos se clasifican dentro 
del modernismo, la crítica tiende a trazar una diferencia entre ellos según su mayor cercanía a los movimientos poéticos franceses finiseculares. Así, se dice que Silva tenía mayor afinidad con el simbolismo, mientras que Valencia estaría más influenciado por los parnasianos.

Ambos poetas, como era propio de la época, hicieron el viaje obligado a Europa, participaron de salones, se empaparon de lleno de las modas literarias y artísticas. Pero la experiencia europea los marcará de manera muy distinta. Mientras Silva regresa a Bogotá tras un año en la capital francesa (1884-1885), con su sensibilidad artística exacerbada, y se encuentra con las penurias económicas de su familia, Valencia viaja durante tres años en misión diplomática por Inglaterra, Francia, Alemania y Suiza y vuelve a Colombia para insertarse en el mundo político como candidato a la presidencia. Estas diferencias biográficas dejarán también su impronta en las respectivas obras, y, adicionalmente, permiten ilustrar lo que caracterizaba el ambiente literario, intelectual y político de la así llamada Atenas Suramericana.

Bogotá se preciaba de ser una ciudad con una gran cultura, en cuyos cenáculos departían hombres de gran erudición. Tal vez la figura más importante en la última década del siglo XIX era Miguel Antonio Caro (1843-1909), traductor de Virgilio; autor de una Gramática Latina - obra que escribió junto con Rufino José Cuervo (1844-1911) - , y de un Tratado del participio; crítico de las licencias que se tomara Andrés Bello (1781-1865) con la norma en su Gramática de la lengua castellana destinada al uso de los americanos; redactor de la Constitución de la República de Colombia de 1886, y vicepresidente y presidente de la República (1892-1898). Caro conjugaba al político y al hombre de letras y dominaba tanto el panorama político como el cultural. En lo político, se le considera el hombre que unifica una nación fragmentada alrededor de dos principios fundamentales: la lengua y la religión. Así, Caro se erige como la figura central de lo que se conoce como el proyecto hispano-católico de la nación.

Este es el medio al que regresa Silva. Bogotá era una ciudad gris, a dos mil seiscientos metros sobre el nivel del mar, y que se distinguía, como señalara alguna vez García Márquez, por sus lúgubres campanarios de iglesia. El ambiente cultural del que tanto se preciaban los bogotanos le parecía opresivo y en él se sentía como un descastado. Nada lo expresa más claramente que la figura de José Fernández, el personaje de su novela póstuma De sobremesa (1925). Para Valencia, en cambio, este es el lugar de sus actividades, un entorno al que se ajusta y en el que se encuentra a gusto.

Ciertamente, sería un exceso afirmar que de sus experiencias de vida surgen inevitablemente sus posturas poéticas. Pero es pensable que en un ambiente poco 
dado a la experimentación y al cambio como el bogotano finisecular, Silva era una figura incómoda, incluso escandalosa, mientras que Valencia representaba, desde todo punto de vista, lo más preciado de la rancia aristocracia nacional. La obra poética de cada uno de ellos es, cuidándonos de caer en causalidades deterministas, un reflejo de su lugar social. Silva es, sin duda, el poeta. Su temprana y trágica muerte lo envuelve, además, en un halo de misterio, lo hace casi irreal. Con Silva termina esa visión de lo poético, lírica, decadentista, sensual y simultáneamente irónica, con toques incluso de crítica social.

Valencia, el diplomático, el político, se posiciona como la gran figura de las letras tras la muerte de su contemporáneo más talentoso y se convierte en el parámetro de la poesía venidera. Una poesía cincelada, marmórea, despojada de todo toque sarcástico, erótico o dramático. Valencia se nutre de las mismas fuentes que los modernistas y de los modernistas mismos, pero establece con la poesía una relación decorativa y funcional, al servicio de las élites en el poder. Es decir, su poesía se adorna de recursos parnasianos, pero su poética se distancia radicalmente de los propósitos manifiestos de la estética modernista. ${ }^{2}$

De alguna manera, las diferencias entre las figuras de Silva y Valencia marcarán las posturas poéticas de las sucesivas generaciones de poetas a lo largo de la primera mitad del siglo XX, entre contestatarios y oficialistas.

\section{La generación del Centenario}

La generación del Centenario, la primera del siglo XX, fue conformada en sus inicios por un grupo de jóvenes escritores que se acercaron con el deseo de publicar la revista literaria Cultura. Pese a que los números de la revista fueron pocos, y a que tuvo una vida corta, Cultura logró reunir al grupo bajo la dirección de Luis Eduardo Nieto Caballero (1888-1957), quien dio el nombre de "centenaristas" a sus compañeros de aventura editorial (Brubaker 75).

Esta generación ha tenido una presencia mediana en las historias de la literatura colombiana si la comparamos con la enorme relevancia que se la ha concedido a la llamada generación de Los Nuevos. Se considera que esta última es la que introduce una visión de vanguardia estética como elemento concomitante de la construcción de una Colombia moderna, en la que se dejarían atrás las categorías decimonónicas, para pasar a indagar por la complejidad social y estética del mundo contemporáneo. Sin embargo, hay que admitir que los

2 Véase Rubén Darío, "Palabras liminares" (1977), el equivalente a su manifiesto poético. Véase, también, Rama. 
así llamados centenaristas tuvieron un papel en el proceso intelectual de los albores del siglo XX.

Dentro de la generación del Centenario se incluyen los nombres de novelistas, artistas, poetas, abogados y futuros políticos. Algunos de los nombres más reconocidos de las letras de esa generación son los de Tomás Rueda Vargas (18791943), Miguel Rasch Isla (1887-1953), José Eustasio Rivera (1888-1928) —autor de La vorágine (1924) - y Eduardo Castillo (1889-1938). También pertenecieron a este grupo futuros presidentes de la república, como Laureano Gómez (18891965), Eduardo Santos (1888-1974) y Alfonso López Pumarejo (1886-1959), así como el historiador Raimundo Rivas (1889-1946), el sociólogo Luis López de Mesa (1884-1967) y los hermanos Luis Eduardo (188-1957) y Agustín Nieto Caballero (1889-1975) — periodista y educador, respectivamente, y figuras destacadas en el panorama de la cultura colombiana de los inicios del siglo XX-. En realidad más coetáneos que contemporáneos estética e ideológicamente, varios de estos nombres no podrían considerarse como relacionados o susceptibles de una filiación literaria si no fuera por el hecho meramente cronológico.

Para Brubaker (76), es necesario estudiar a la Generación del Centenario, más que como generación literaria, como un grupo de pensadores, escritores y políticos que desearon construir una nueva nación, y que debe ser abordada en su totalidad y diversidad tanto como en sus similitudes. Esta generación continuó la discusión entre los principios de libertad y orden en torno a los cuales giraron los debates políticos de finales del siglo XIX y los adoptaron como principios rectores de una nueva Colombia que se abría a las realidades del siglo XX. Donde Los Nuevos propagaban aires de ruptura e innovación, Los Centenaristas entendían la necesidad de comprender las transformaciones sociales, aunque a la vez propugnaban por un orden basado en principios tradicionales.

En el aspecto estético propiamente dicho, a pesar de haber sido considerados como continuadores de la estética modernista, hay que advertir que muchos de ellos retornaron a un romanticismo tardío y a una visión relativamente anacrónica de la creación. Para David Jiménez Panesso, Los Nuevos - la generación inmediatamente siguiente a la de los escritores centenaristas - adoptan una visión crítica ante el anquilosamiento estético y el ideal conservador que distinguió a la generación del Centenario:

Cuando Jorge Zalamea pretende resumir las objeciones de sus coetáneos en contra de la generación anterior, la del Centenario, más que esbozar una crítica del Modernismo, lo que señala es más bien su traición al programa modernista: un falso romanticismo y cierta despreocupación provinciana por los problemas del mundo contemporáneo eran los dos grandes defectos de sus predecesores, 
algo que no podría haberse imputado a Silva o a Sanín Cano. El ambiente literario en el que aparece la poesía de un León de Greiff estaba aún dominado por amaneramientos y exageraciones de baja estirpe romántica y apenas recibía sacudones de liberación modernista. (Jiménez, Historia de la crítica 169)

\section{La generación de Los Nuevos}

A esta generación del Centenario, que puede considerarse más cercana a valores tradicionales y a una estética decimonónica, donde conviven de manera indistinta elementos románticos de filiación francesa y española, así como realistas y del modernismo de línea rubendariaca y martiana, le sigue la llamada generación de Los Nuevos, conformada por algunos de los poetas más notables de la poesía colombiana de la primera mitad del siglo XX: León de Greiff, Luis Vidales, Jorge Zalamea, Luis Tejada y Rafael Maya (1897-1980).

Los Nuevos supieron detectar el pulso de su tiempo, y en su convicción de renovación y deseo de modernidad se hallan algunas de las claves para entender el significativo papel que tuvieron en la recomposición del panorama poético colombiano de las primeras décadas del siglo XX. Su obra más significativa fue publicada en las décadas de los años veinte y treinta, y consiguieron ofrecer una propuesta estética en la que las conquistas del surrealismo, la particular manera de entender el espíritu literario de vanguardia en Europa y un modo propio de hacer frente a los procesos de modernización, urbanización acelerada y tensiones políticas en conflicto cristalizaron en un lenguaje dúctil, en ocasiones todavía cercano a las búsquedas del Modernismo de la segunda mitad del siglo XIX, pero también permeado por un deseo de recuperación de formas arcaizantes, revaloradas desde una nueva perspectiva, que se une a la utilización de neologismos y una aportación original de elementos del lenguaje musical del siglo XIX, en el caso de las Tergiversaciones o las Variaciones alredor (sic) de nada de León de Greiff; y al uso de un lenguaje satírico, lleno de humor e ironía, preciso y sardónico, cercano al del mundo de las Greguerías de Ramón Gómez de la Serna, en el del famoso libro Suenan timbres de Luis Vidales. También Jorge Zalamea, el traductor de Saint-John Perse, uno de los modelos indiscutibles del versículo propio de los poemas iniciales de Álvaro Mutis, crea una obra de poesía donde el elemento declamatorio y político, así como la aportación sincrética de otras culturas, la convierten en una de las más populares en su tiempo, el reconocido libro El sueño de las escalinatas, y con posterioridad el ensayo antológico La poesía ignorada y olvidada. 
Para Los Nuevos la novedad compositiva en poesía es un valor estético, y su deseo de contemporaneidad más o menos consciente, junto con una pretensión de originalidad que los distancia de manera significativa de los poetas de la Generación del Centenario, los convierte en la primera generación de la poesía colombiana después de Silva en la que la vivencia de la modernidad es un asunto decisivo en su afirmación y presencia como creadores. La poesía habla de un tiempo nuevo con un remozado lenguaje, que los hace distintos en el panorama de la poesía colombiana.

\section{La generación de Piedra y Cielo}

Luego de la invitación a una modernidad literaria de los poetas que conforman la generación de Los Nuevos, asistimos al regreso de una visión conservadora de la realidad, en la que el elemento hispánico, convocado en algunas de sus formas más tradicionales, volverá en la generación posterior, la de Piedra y Cielo, llamada así como homenaje al libro de Juan Ramón Jiménez. Los miembros más conocidos de esta generación son los poetas Eduardo Carranza, Jorge Rojas, Arturo Camacho Ramírez y Carlos Martín, poetas de una decidida vocación hispanófila, y cultores de una visión de la realidad en muchas ocasiones anacrónica o francamente retardataria.

En el famoso y citado texto "Un caso de bardolatría" (1941) de Eduardo Carranza - el miembro más conocido de los poetas de Piedra y Cielo—, asistimos a una temprana diatriba contra la marmórea y fría poesía del modernista Guillermo Valencia - el gran pontífice de la poesía colombiana en las primeras décadas del siglo $\mathrm{XX}$ - y a una defensa a ultranza del sentimiento y la autenticidad como fuentes de la poesía de lo humano, que los piedracielistas descubrieron en la poesía de los autores españoles de la Generación del 27, a quienes admiraron de manera significativa y constante.

Sin embargo, antiguas formas de metrificación del verso, un aparato metafórico bastante reducido y una actitud política de nostalgia por el pasado hispánico perdido, nos muestran bien a las claras el movimiento pendular de la poesía colombiana del siglo XX: de la generación del Centenario - cercana al poder político de la Regeneración, muchos de cuyos representantes cultivaron una poesía cansina y repetitiva - a Los Nuevos - una generación deseosa de un encuentro con la modernidad y creadora de un lenguaje más dúctil y complejo, que huye del adocenamiento expresivo - y de vuelta a una visión de la creación poética más tradicional, con una vocación panhispánica férrea y afín a un orden político y social preterido, encarnada en la obra de los autores de Piedra y Cielo. 


\section{La generación de Mito}

Con la siguiente generación poética, la que se agrupó en torno de la revista Mito, conformada por escritores coetáneos de Álvaro Mutis (1923-2013), el movimiento pendular antes descrito vuelve a operar. Asistimos a un momento de la cultura y la literatura colombianas en el que el deseo de renovación de las formas del pensamiento, el ansia de transformación social y la búsqueda de un diálogo cosmopolita con otras lenguas y tradiciones son categorías que se convierten en una marca que se identifica con facilidad en los propósitos de la revista. Se conforma entonces una visión de mundo crítica, afín al pensamiento moderno, cultora de un lenguaje que es deudor de las nuevas expresiones estéticas, y que distingue al estilo de estos poetas, así como a la obra de los narradores, ensayistas, sociólogos y artistas plásticos que son incluidos dentro de la generación.

El escritor que funda y dirige la revista Mito, publicada de 1955 a 1962, y una de las figuras intelectuales más brillantes de esta época es Jorge Gaitán Durán (1924-1962). Otros de los escritores relacionados con la revista son Hernando Valencia Goelkel (1928-2004), quien fue su subdirector y editor, así como Eduardo Cote Lamus (1928-1964), Jorge Eliécer Ruiz (1931-2011), Rogelio Echavarría (1926), Rafael Gutiérrez Girardot (1928-2005), Fernando Arbeláez (1924-1995), Fernando Charry Lara (1920-2004); en sus páginas publicaron también Héctor Rojas Herazo (1921-2002) y Gabriel García Márquez (1927-2014). Como lo veremos, Álvaro Mutis tendrá un deseo repetido de deslindarse de la generación de Mito, aunque su coetaneidad con la mayoría de estos poetas, narradores y ensayistas, así como el hecho de que uno de los libros más importantes del primer periodo de su poesía, la Reseña de los hospitales de Ultramar, haya sido publicado en la revista, es la base biográfica que sirve de basamento para realizar el trazo de relaciones sugestivas de nuestro autor con la generación de Mito, aparte de la cercanía cronológica y las realidades editoriales de cercanía.

La poesía que defendió Mito estuvo vinculada con una expresión a tono con la conciencia de disolución, irracionalismo y pérdida de centro que recorre buena parte de la visión de mediados del siglo XX, aunque atendiendo a principios compositivos en los que la manifestación de la experiencia vivida y la construcción de un mundo metafórico sólido no se conviertan en adalides de una poesía hermética o de un culturalismo extremo. En muchos de los poetas que publicaron en la revista se advierte la presencia de una vanguardia que hace énfasis en la modernización formal y temática de la expresión poética de su época, pero teniendo presente de manera constante la figura de un lector con el que se pretende un vínculo empático, tanto afectivo como conceptual. La tradición literaria, sin embargo, fue también defendida y considerada un 
valor en sus páginas, y la relación, personal y estética, de los miembros de Mito con los poetas españoles de la Generación del 27 - en aquella dimensión que los concibe como voces activas de un "vanguardismo de la tradición", en términos de Rafael Alberti (1902-1999) - los convierte en adalides de la expresión moderna de una nueva tradición literaria. En Mito no se propugnó por la imposición, sin embargo, de una tendencia única de concepciones ideológicas o estéticas, y este pluralismo es una de las fortalezas que marcó su historia y presencia posterior de una manera más significativa.

Hay que señalar también que, como anota Pedro Sarmiento Sandoval, los poetas de Mito pertenecían a clases sociales privilegiadas; la formación profesional como abogados de muchos de ellos, así como el deseo de participar en política; su presencia como activos adversarios de las dictaduras militares; su diversidad estética, termina, en últimas, haciéndolos protagonistas de una aventura generacional común, a pesar de las divergencias en términos de concepción poética. Asimismo, fue también característico el deseo de abrir las tradiciones poéticas de sus países a un mundo cosmopolita y de carácter internacional, lo cual se hizo evidente en el papel que cumplieron como traductores de poetas de otras lenguas. Igualmente, mostraron un interés constante por reflexionar de manera argumentada y crítica sobre su propia creación, lo que los hizo rigurosos con su poesía, que se distingue por un lenguaje marcado por una exigencia creativa poderosa y una distancia importante de las corrientes estéticas que habían exagerado el credo surrealista y que terminaron llevando a un irracionalismo que en muchas ocasiones entró en contacto dañino con la reacción estética y política. Fueron, de otro lado, escritores marcados por un compromiso ético como condición necesaria para la escritura poética; su actitud existencial los llevó a exigirse una forma de excelencia humana, y los convierte en personajes que marcaron una época, representativos de una visión de la poesía donde literatura y vida se complementan de una manera necesaria y orgánica (Sarmiento Sandoval).

Es fundamental comprender, por un lado, la importancia de Mito para el devenir académico y cultural de Colombia y, por el otro, la discusión que se genera alrededor de si puede ubicarse a Álvaro Mutis en dicha generación a pesar de su reticencia. Hay, incluso, una tercera arista: la cuestión de la modernidad y la posmodernidad literaria en Colombia, pues frente a eso habría, en la obra del bogotano, una respuesta con respecto a su postura ante estas categorizaciones.

\section{Ubicación de la obra de Mutis en la tradición poética colombiana}

Álvaro Mutis es un conservador en política, defensor del orden tradicional hispánico que representó la Regeneración política en la historia de los últimos años del 
siglo XIX y las primeras décadas del siglo XX en Colombia, y, de manera simultánea, un escritor que practica una expresión renovadora del lenguaje poético, cuya ruptura con los principios estéticos de la generación de Piedra y Cielo lo convierte en un autor moderno, que tiene una cercanía estética con procedimientos del surrealismo, y cuyo claro interés por hablar de un mundo en disolución y disgregado nos lo acerca a una vivencia más contemporánea de lo poético. Su estética es moderna y dúctil; allí, la desesperanza y la angustia existencial ocupan un sitio decisivo, con una poesía alejada del ánimo declamatorio y convencional de la generación de sus maestros.

En él parecen convivir los dos rostros de los poetas que signan el recorrido de la poesía en nuestro país a lo largo de más de cincuenta años: el del conservador y estatuario Guillermo Valencia, candidato a la presidencia de la República por el partido conservador, devoto lector de los parnasianos y católico practicante; y el de aquel José Asunción Silva que conoció, como pocos de sus contemporáneos, la poesía de los simbolistas franceses, asistió a los Martes de Mallarmé durante su estancia parisina, y defendió una visión renovadora, irónica y crítica del hecho poético, abriendo la poesía colombiana a la modernidad. En Mutis el esquema de relevos de generaciones conservadoras reemplazadas por generaciones modernizadoras, que hemos planteado al inicio de esta reflexión, no opera de manera tan clara, y debemos acercarnos a su poesía advirtiendo la complejidad que entrañan su visión de mundo y su comprensión del hecho poético.

Uno de los principios centrales de la escritura en la obra de Mutis corresponde a la insistencia en alejarse de discusiones políticas o ideológicas, de la literatura de ideas, contrarias al pensamiento estético, que es la base filosófica de su producción literaria. Es quizás este asunto una de las razones por las cuales se ha visto que Mutis ha aceptado la inclusión en la generación de Mito, más por comodidad que por convicción, precisamente por su rechazo a cualquier intención de compromiso político (Laverde Ospina). Por otro lado, como señala Martha Canfield, "el espíritu cosmopolita de Mito es una de las características dominantes de la personalidad de Mutis", así como el hecho de que "su crecimiento intelectual es inseparable de sus raíces, sólidamente aferradas a su tierra de origen (72).

Es cierto, entonces, que generacional y vitalmente existió una cercanía de nuestro autor - en un sentido amplio y contextual - con Mito, y que los lazos intelectuales y biográficos que podemos encontrar entre Mutis y el grupo de la revista fundada por Jorge Gaitán Durán y Hernando Valencia Goelkel no pueden ser desconocidos. 


\section{Conclusión}

Dos tipos de lectura de juventud marcarán una indeleble impronta en la poesía de Mutis: por un lado, la poesía surrealista francesa que dejará huellas en su manera de entender la imagen del poema, de naturaleza irracional y arbitraria, y, de otro, la obra del premio Nobel Saint-John Perse (1887-1975), conocido de manera inicial en las versiones que de su obra hará el poeta Jorge Zalamea. La obra del autor nacido en la isla de Guadalupe, y su particular visión del mundo del Caribe, pleno de desbordamiento sensorial, una reiteración del valor simbólico de la niñez como fuerza que hace posible la creación, y una conciencia reiterada del poder de disolución que habita el mundo del trópico son todos elementos que nutrirán la obra poética de su primer periodo, y la acercarán a la del autor guadalupano.

$\mathrm{Su}$ visión poética inicial del mundo del trópico como deterioro y espacio para la ruina, la reflexión sobre el sentido de la desesperanza como conciencia lúcida del hombre ante la inevitabilidad de la disolución y la muerte como destinos finales de la existencia, una pertinaz fidelidad a cierta visión anacrónica de la historia, el gusto por asuntos de tema histórico que se hará muy presente en su poesía en distintos momentos de su producción, convivirán con una visión nostálgica de un mundo abolido que el poeta desea como regreso posible a unos orígenes imaginados o soñados. La aparición de España como un símbolo de reconciliación y sosiego luego de haber vivido en un estado de zozobra y sinsentido lúcido y angustiado, implacable con los propios temores y falencias, la idealización de ciertas formas de la fe y los antiguos órdenes políticos como posibilidad de reencuentro y afirmación vital ante la evidencia del caos del mundo contemporáneo, son elementos de naturaleza paradójica, que lo convierten en un poeta con una voz única en el panorama de la historia de la poesía colombiana.

La existencia de estos elementos en convivencia permiten pensar que en él el deseo de modernidad, la creación de un lenguaje poético cercano al de un mundo en fragmentación, complejo, convive con la existencia de una visión más conservadora de la sociedad, deseosa de reactualizar el sueño hispánico como una posibilidad de reencuentro con sus orígenes familiares. En la obra de Mutis la modernidad y la tradición conviven de manera constante, y permiten que lo entendamos como un autor de síntesis, que no cumple a cabalidad con el esquema pendular - de relevo entre cultores de principios conservadores sociales y artísticos y creadores signados por una visión modernizadora de la realidad y los principios compositivos textuales-, planteado aquí como principio definitorio de la alternancia entre generaciones poéticas en la historia de la literatura del siglo XX en Colombia. 


\section{Obras citadas}

Brubaker, George. "Una «minoría excelente»: la generación del Centenario y su impacto en la política colombiana”. Universitas Humanística 26.26 (1986): 73-80. Impreso.

Canfield, Martha. "De la materia al orden: la poética de Álvaro Mutis". Inti: Revista de Literatura Hispánica 51 (primavera, 2000): 69-88. Impreso.

Castillo Mier, Ariel. "Recouvrances: Un texto clave en la trayectoria poética de Álvaro Mutis". Caravelle 74 (2000): 241-244. Impreso.

Darío, Rubén. Poesía. Ed. Ernesto Mejía Sánchez. Caracas: Biblioteca Ayacucho, 1977. Impreso.

Jiménez, David. Historia de la crítica literaria en Colombia. Bogotá: Universidad Nacional de Colombia, 1992. Impreso.

Jiménez, David. "Sobre la presente antología". Antología de la poesía colombiana. Bogotá: Editorial Norma, 2008. Impreso.

Jurado Valencia, Fabio. "Álvaro Mutis y el grupo de la revista Mito: tradición e innovación en la poesía colombiana". Gaviero. Ensayos sobre Álvaro Mutis. Ed. Diego Valverde Villena. Madrid: Verbum, 2014. 93-98. Impreso.

Laverde Ospina, Alfredo. "Afinidades y oposiciones en la narrativa colombiana: una lectura de Jorge Isaacs, José Asunción Silva, Gabriel García Marquez y Álvaro Mutis". Tesis Doctoral, Faculdade de Filosofia, Letras e Ciências Humanas, Universidad de São Paulo, São Paulo, 2006. doi:10.116o6/T.8.2006.tde-08062006-002046. Web.

Rama, Ángel. Rubén Darío y el modernismo (circunstancia socio-económica de un arte americano). Caracas: Alfadil Ediciones, 1985. Impreso.

Romero, Armando. "Los poetas de Mito". Revista Iberoamericana 50.128-129 (1984): 689-755. Impreso.

Sarmiento Sandoval, Pedro. La revista Mito en el tránsito de la modernidad a la posmodernidad literaria en Colombia. Bogotá: Instituto Caro y Cuervo, 2006. Impreso.

Trujillo, Patricia. "Períodos y generaciones en la historia de la poesía colombiana del siglo XX". Literatura: teoría, historia, crítica 5 (2003): 127-146. Impreso. 